Vol 11, Issue 9, 2018

\title{
HIGH-PERFORMANCE THIN-LAYER CHROMATOGRAPHY ANALYSIS AND FREE RADICAL SCAVENGING POTENTIAL OF SOUTH INDIAN ORTHODOX BLACK TEA
}

\author{
MAHALAKSHMI RAJAMANI ${ }^{1 *}$, KALAIVANI KRISHNASAMY ${ }^{2}$, NISHADH ABUBAKKER ${ }^{3}$ \\ ${ }^{1}$ Department of Biochemistry, CMS College of Science and Commerce, Coimbatore, Tamil Nadu, India. ${ }^{2}$ Department of Biochemistry, \\ Kongunadu Arts and Science College, Coimbatore, Tamil Nadu, India. ${ }^{3}$ Department of Food Processing Technology, Karunya Institute of \\ Technology and Sciences, Coimbatore, Tamil Nadu, India. Email: mahaamakes@gmail.com
}

Received: 22 June 2018, Revised and Accepted: 1 August 2018

ABSTRACT

Objective: The objective of this study was to evaluate the free radical scavenging potential and high-performance thin-layer chromatography (HPTLC) fingerprinting of the ethanolic extract of south Indian orthodox black tea (OBT).

Methods: Phytochemical analysis was carried out using standard methods, and free radical scavenging activity of the extract was determined using 2,2-diphenyl-1-picrylhydrazyl (DPPH), nitric oxide (NO), superoxide anion (SOD), and hydroxyl radical scavenging capacities. The ethanolic extract of OBT was loaded in the pre-coated HPTLC plates (silica gel 60 F 254) E-MERCK KGaA. HPTLC was carried out with toluene: ethyl acetate: diethylamine (7:2:1), chloroform: methanol:formic acid (8.5:1.0:0.5), and butanol: isopropyl alcohol (1:1) as mobile phase for alkaloids, flavonoids, and terpenoids, respectively.

Results: HPTLC results confirmed that the extract contained several potential active components such as flavonoids, alkaloids, and terpenoids as the slides revealed multicolored bands of varying intensities. Extract of OBT reliably showed the total phenolics $132.27 \mathrm{mg} / \mathrm{g}$, flavonoids $72.52 \mathrm{mg} / \mathrm{g}$, and alkaloids $66.01 \mathrm{mg} / \mathrm{g}$ of dry matter. The IC ${ }_{50}$ value of OBT for DPPH was found to be $372.22 \mu \mathrm{g} / \mathrm{ml}$, SOD $311.93 \mu \mathrm{g} / \mathrm{ml}, \mathrm{NO} 362.17 \mu \mathrm{g} / \mathrm{ml}$, hydroxyl radical $342.14 \mu \mathrm{g} / \mathrm{ml}$, and reducing power $178.54 \mu \mathrm{g} / \mathrm{ml}$.

Conclusion: The HPTLC fingerprinting profile developed for ethanolic extract will help in proper identification and quantification of marker compounds. The ethanolic extract of OBT was found to possess a wide range of phytochemicals with excellent antioxidant properties. This information may help to choose the best beverage to be consumed in the future.

Keywords: Orthodox black tea, High-performance thin-layer chromatography, Alkaloids, Flavonoids, Terpenoids.

(c) 2018 The Authors. Published by Innovare Academic Sciences Pvt Ltd. This is an open access article under the CC BY license (http://creativecommons. org/licenses/by/4.0/) DOI: http://dx.doi.org/10.22159/ajpcr.2018.v11i9.28067

\section{INTRODUCTION}

Plants are the richest source of phytochemicals. The world is overwhelmed with the great variety of natural vegetation, of which few are used in traditional medicine, in curing various ailments. Secondary metabolites possess toxicological pharmacological and ecological importance [1]. In recent years, phytotherapeutics play vital role in concern with health aid due to the presence of good radical scavengers which exhibit a great variety of therapeutic effects [2].

Tea is reported to contain nearly 4,000 active principles, of which onethird is contributed by polyphenols. The natural polyphenols present in tea are the flavonoids which are commonly branded as total catechins. The flavonoids (and their fraction, catechins) are the essential phenolic compounds in tea responsible for antioxidant activities such as neutralizing the free radicals which have been produced during the process of metabolism [3]. All the varieties of teas are produced from the same plant. The variety and quality of the tea are decided based on the level of fermentation, i.e., the processing techniques involved. Unfermented teas are rapidly dried, which quickly inactivate the enzyme polyphenol oxidase. This possesses a very high quantity of polyphenolic compounds, when compared to semi-fermented tea, in which polyphenols undergo partial oxidation followed by complete oxidation in black tea $[4,5]$.

Throughout the world, about $78 \%$ of completely fermented tea (black tea) was consumed by the people in Western and Asian countries. 20\% of unfermented tea (green tea) was consumed by the population in Asian countries. $2 \%$ of semi-fermented tea was consumed mainly by
China and Taiwan [6]. It was found that the infusion of tea holds more water-soluble polyphenols, particularly flavonols, flavonol gallate, and flavonol glycosides. It also contains catechins which consist of epigallocatechin, epicatechin, epigallocatechin gallate, and epicatechin gallate [7].

The present study was focused on screening the bioactive principles present in the ethanolic extract of orthodox black tea (OBT). Highperformance thin-layer chromatography (HPTLC) fingerprint profile was also carried out to mark the signature of classes of secondary metabolites such as alkaloids, flavonoids, and terpenoids followed by the determination of free radical scavenging activity.

\section{MATERIALS AND METHODS}

Collection and preparation of tea powder

The South Indian OBT (BOP grade) was purchased from the local market. About $250 \mathrm{~g}$ of OBT powder was first defatted with petroleum ether $\left(40-60^{\circ} \mathrm{C}\right)$, and then, it is extracted in Soxhlet apparatus with ethanol. The extract was dried under reduced pressure at low temperature $\left(40-50^{\circ} \mathrm{C}\right)$.

\section{Determination of total phenolic content}

Total phenolic content of the extract was determined by the FolinCiocalteu reagent method [8]. About $1 \mathrm{ml}$ of the extract/standard solutions with different concentrations was mixed with $5 \mathrm{ml}$ of FolinCiocalteu reagent (previously diluted with water $[1: 10, \mathrm{v} / \mathrm{v}]$ ) and $4 \mathrm{ml}$ of sodium carbonate $(7.5 \%)$. The mixtures were vortexed for a few seconds and allowed to stand for $30 \mathrm{~min}$ at $20^{\circ} \mathrm{C}$ for color development. 
Absorbance of samples and standard was measured at $765 \mathrm{~nm}$ using a spectrophotometer against blank. The total phenolic content of the extract was calculated as the gallic acid equivalent (GAE).

\section{Determination of total flavonoid content}

The total flavonoid content in the ethanolic extract of OBT was determined colorimetrically using a slightly modified method [9]. $0.5 \mathrm{ml}$ of diluted extract was mixed with $0.5 \mathrm{ml}$ of methanol, $50 \mu \mathrm{l}$ of $10 \%$ aluminum chloride, $50 \mu \mathrm{l}$ of $1 \mathrm{M}$ potassium acetate, and $1.4 \mathrm{ml}$ of water. The mixtures were allowed to stand at room temperature for $30 \mathrm{~min}$. After incubation, absorbance was read colorimetrically at $415 \mathrm{~nm}$ and the total flavonoid content in the extract was reported as quercetin equivalent $(\mathrm{QE})$.

\section{Determination of alkaloid}

The plant extract about $1 \mathrm{mg}$ was dissolved in dimethyl sulfoxide and added $1 \mathrm{ml}$ of $2 \mathrm{~N}$ hydrochloric acid and filtered. The filtrate was transferred to a separating funnel to which $5 \mathrm{ml}$ of bromocresol green, $5 \mathrm{ml}$ of phosphate buffer solution, and $5 \mathrm{ml}$ of chloroform were added. After shaking, the chloroform fraction alone was collected in a $10 \mathrm{ml}$ standard flask and made up to $10 \mathrm{ml}$ with chloroform. Caffeine was used as the standard. The absorbance of the test and standard solution was quantified against blank at $470 \mathrm{~nm}$. The total alkaloid content was expressed as mg of caffeine equivalent/g of extract [10].

\section{2,2-diphenyl-1-picrylhydrazyl (DPPH) radical scavenging activity} The free radical scavenging capacity of the extract was determined using DPPH [11]. The mixture of DPPH $(0.1 \mathrm{mM})$ in methanol was prepared, and $4 \mathrm{ml}$ of this solution was added to $1 \mathrm{ml}$ of sample solution in methanol at different concentrations $(50-250 \mu \mathrm{g} / \mathrm{ml}) .30 \mathrm{~min}$ later, the absorbance was measured at $517 \mathrm{~nm}$ at room temperature using a Lambda UV-Vis spectrophotometer (PerkinElmer). Lower absorbance of the reaction mixture indicates a higher free radical scavenging activity. Ascorbic acid was used as a standard.

DPPH scavenged $(\%)=([$ Abs control - Abs test $] /$ Abs control $) \times 100 \%$

Where Abs control is the absorbance of the control reaction, and Abs test is the absorbance of the extract/standard.

\section{Hydroxyl radical scavenging activity}

Hydroxyl radical is one of the potent reactive oxygen species in the biological system. It reacts with polyunsaturated fatty acid unit phospholipids of the cell membrane and injures the cell [12]. Samples of various concentrations were taken in the tube and added $1 \mathrm{ml}$ of $1.5 \mathrm{mM}$ ferrous sulfate, $0.7 \mathrm{ml}$ of $6 \mathrm{mM}$ hydrogen peroxide, and $0.3 \mathrm{ml}$ of $20 \mathrm{mM}$ sodium salicylate. The solutions after mixing were incubated at $37^{\circ} \mathrm{C}$ for $1 \mathrm{~h}$. After incubation, the absorbance was read colorimetrically at $562 \mathrm{~nm}$, against a blank sample. Ascorbic acid [13] was used as a positive control. Percentage inhibition was calculated by comparing the test and blank solutions. The effect of scavenging was compared with the standard antioxidant $\alpha$-tocopherol.

\section{Superoxide radical scavenging activity}

The scavenging activity toward the superoxide radical was measured in terms of the inhibition of generation of $02 *$. The assay was performed using alkaline DMSO method [14]. Potassium superoxide and DMSO were allowed to stand in contact for $24 \mathrm{~h}$, and the solution was filtered immediately before use. Filtrate $(200 \mu \mathrm{l})$ was added to $2.8 \mathrm{ml}$ of an aqueous solution containing NBT $(500 \mu \mathrm{M})$, EDTA $(10 \mu \mathrm{M})$, and potassium phosphate buffer $(10 \mathrm{mM})$. Test compounds ( $1 \mathrm{ml})$ at various concentrations $(1-1000 \mu \mathrm{g} / \mathrm{ml})$ were added, and the absorbance was recorded at $560 \mathrm{~nm}$ against a control in which pure DMSO was added instead of alkaline DMSO. The results were compared with the reference antioxidant quercetin.

\section{Nitric oxide (NO) radical scavenging activity}

NO produced from sodium nitroprusside in aqueous solution at physiological $\mathrm{pH}$ acts together with oxygen to produce nitrite ions, which were measured using the Griess reaction reagent [15]. $2 \mathrm{ml}$ of $10 \mathrm{mM}$ sodium nitroprusside and $0.5 \mathrm{ml}$ phosphate buffer are added to $2 \mathrm{ml}$ of extract and reference compound in different concentrations $(20-100 \mu \mathrm{g} / \mathrm{ml})$. The resulting solutions are then incubated at $25^{\circ} \mathrm{C}$ for $60 \mathrm{~min}$. To $5 \mathrm{ml}$ of the incubated sample, $5 \mathrm{ml}$ of Griess reagent was added and the absorbance of the chromophore formed is measured at $540 \mathrm{~nm}$. A similar procedure is repeated with methanol as blank, which serves as control. The percentage inhibition of the nitrite oxide generated is measured by comparing the absorbance values of control and test preparations. Ascorbic acid was used as a positive control.

\section{Reducing power assay}

Reducing power was carried out using the method reported by Yildirim et al. [16]. $1 \mathrm{ml}$ of the extract and its subfractions $(1-1000 \mu \mathrm{g} / \mathrm{ml})$ were mixed with $2.5 \mathrm{ml}$ of phosphate buffer $(0.2 \mathrm{M}, \mathrm{pH} 6.6)$ and $2.5 \mathrm{ml}$ of potassium ferricyanide. The mixture was then incubated at $50^{\circ} \mathrm{C}$ for $20 \mathrm{~min}$. To this mixture, $2.5 \mathrm{ml}$ of trichloroacetic acid was added and centrifuged at $3000 \mathrm{rpm}$ for $30 \mathrm{~min}$. Finally, $2.5 \mathrm{ml}$ of the supernatant solution was collected and mixed with $2.5 \mathrm{ml}$ of distilled water and $0.5 \mathrm{ml}$ of ferric chloride, and the absorbance was measured at $700 \mathrm{~nm}$. Ascorbic acid was used as a standard and phosphate buffer as the blank solution.

\section{HPTLC fingerprint profile}

The HPTLC analysis of the ethanolic extract of OBT was carried out to confirm the presence of a variety of phytochemicals present. The ethanolic extract of OBT was loaded in the pre-coated HPTLC plates (silica gel $60 \mathrm{~F} 254$ ) E-MERCK KGaA and plate size $10 \times 10 \mathrm{~cm}$. The TLC plates loaded with sample were kept in twin trough chamber which was saturated with solvent vapors. HPTLC was carried out with toluene: ethyl acetate: diethylamine (7:2:1), chloroform: methanol:formic acid (8.5:1.0:0.5), and butanol: isopropyl alcohol (1:1) as a mobile phase for alkaloids, flavonoids, and terpenoids, respectively. The developed plates were dried by hot air oven at $60^{\circ} \mathrm{C}$ for $5 \mathrm{~min}$ to make the solvent evaporate from the plate. After drying, the plates were taken for photo documentation (CAMAG TLC Scanner) chamber. The images were taken at UV $254 \mathrm{~nm}$ and UV $366 \mathrm{~nm}$

\section{Statistical analysis}

Statistical analysis was carried out in triplicates $(n=3)$, and standard error (SE) was calculated. All the data were analyzed using analysis of variance with the statistical software Prism 7.0 version. The analyses were made with $95 \%$ confidence. The significance of differences $(p<0.05)$ between mean values obtained from the experiments was determined by Tukey's test.

\section{RESULTS}

A thorough understanding of their chemical composition is essential for conducting a safety risk assessment. Chemical constituents of processed made tea were performed by many researches, but they are not always exactly similar due to their geographic location. The chemical constituents and their amounts in processed made tea can be different, due to growing conditions, such as climate, soil fertility, harvest season, age of the leaves, degree of fermentation, and the drying process.

\section{Total phenolic content}

The total phenolic content of the ethanolic extract was determined using the Folin-Ciocalteu reagent and expressed as GAE per gram of plant extract. The total phenolic content of the extract was calculated using the standard curve of gallic acid $(y=15.885 \times+10.133$; $R 2=0.0998)$. Ethanolic extract of OBT was found to have $132.27 \pm 1.84 \mathrm{mg}$ of GAE/g of dry matter

\section{Total flavonoid content}

Aluminum chloride colorimetric methods were used to determine the total flavonoid content of the ethanolic extract of OBT. Total flavonoid content was calculated using the standard curve of quercetin $(y=0.461 \times$ -0.141; $\mathrm{R}^{2}=0.977$ ) and expressed as $\mathrm{QE} / \mathrm{g}$ of the plant extract. Ethanolic extract of OBT was found to have $72.52 \pm 2.87 \mathrm{mg}$ of $\mathrm{QE} / \mathrm{g}$ of dry matter. 
Determination of total alkaloid content

The alkaloid contents were examined in plant extracts and expressed in terms of atropine equivalent as $\mathrm{mg}$ of $\mathrm{AE} / \mathrm{g}$ of extract. The highest concentration of alkaloid was measured $66.01 \pm 0.049 \mathrm{mg}$ of extract in ethyl acetate fraction and $32.14 \pm 0.23 \mathrm{mg}$ of $\mathrm{AE} / \mathrm{g}$ of dry matter.

\section{HPTLC analysis}

Alkaloids

The results of phytochemical screening showed that the ethanolic extract of OBT possesses phytoconstituents such as alkaloids,

Table 1: Peak table with Rf values, height, and area of alkaloids and unknown compounds

\begin{tabular}{llllll}
\hline Track & Peak & Rf value & Height & Area & $\begin{array}{l}\text { Assigned } \\
\text { substance }\end{array}$ \\
\hline Standard & 1 & 0.14 & 3.5 & 17438.6 & Colchicine \\
Sample & 1 & 0.07 & 25.7 & 23583.2 & Alkaloid 1 \\
Sample & 2 & 0.11 & 20.5 & 713.9 & Unknown* \\
Sample & 3 & 0.14 & 0.6 & 208.5 & Colchicine \\
Sample & 4 & 0.38 & 5.6 & 8940.9 & Alkaloid 2 \\
Sample & 5 & 0.46 & 111.6 & 2463.2 & Unknown* \\
Sample & 6 & 0.57 & 12.7 & 28578.2 & Alkaloid 3 \\
Sample & 7 & 0.74 & 2.1 & 367.8 & Unknown* \\
Sample & 8 & 1.11 & 3.3 & 3465.4 & Unknown* \\
\hline
\end{tabular}

Rf: Retention factor

Table 2: Peak table with Rf values, height, and area of flavonoids and unknown compounds

\begin{tabular}{llllll}
\hline Track & Peak & Rf value & Height & Area & $\begin{array}{l}\text { Assigned } \\
\text { substance }\end{array}$ \\
\hline Standard & 1 & 0.45 & 10.9 & 31681.7 & Quercetin \\
Sample & 1 & 0.06 & 456.4 & 27562.7 & Flavonoid 1 \\
Sample & 2 & 0.25 & 43.8 & 30624.9 & Flavonoid 2 \\
Sample & 3 & 0.38 & 69.8 & 6244.3 & Unknown* \\
Sample & 4 & 0.43 & 49.5 & 2145.4 & Flavonoid 3 \\
Sample & 5 & 0.47 & 42.9 & 1399.1 & Flavonoid 4 \\
Sample & 6 & 0.55 & 43.1 & 2210.2 & Unknown* \\
Sample & 7 & 0.61 & 104.3 & 3131.4 & Unknown* \\
Sample & 8 & 0.73 & 33.6 & 10656.0 & Flavonoid 5 \\
Sample & 9 & 0.80 & 124.0 & 3785.8 & Unknown* \\
Sample & 10 & 0.94 & 21.7 & 37333.1 & Flavonoid 6 \\
Sample & 11 & 1.01 & 15.4 & 895.8 & Unknown* \\
Sample & 12 & 1.22 & 0.8 & 8441.5 & Unknown* \\
\hline
\end{tabular}

Rf: Retention factor flavonoids, and terpenoids which was determined with the help of HPTLC chromatogram. Various solvent systems were used to examine the secondary metabolites such as alkaloids, flavonoids, and terpenoids. Colchicine, quercitin, and lupeol were the standards used for the analysis.

Table 1 shows the presence of alkaloids in the ethanolic extract of OBT with retention factor (Rf) values such as $0.07,0.11$, and 0.14 . The Rf value of standard colchicines was found to be 0.14 . Chromatogram and the densitogram results (Fig. 2) of the extract of OBT in HPTLC analysis for alkaloids under daylight, $254 \mathrm{~nm}$, and $366 \mathrm{~nm}$ are shown in Fig. 1. Comparing the Rf values of both standard and sample, it reveals that the sample possesses the colchicine. The peaks showed the presence of other alkaloids in the ethanolic extract of OBT.

\section{Flavonoids}

Six different types of flavonoid compounds were found in the ethanolic extract of OBT with the Rf values of $0.06,0.25,0.43,0.47,0.73$, and 0.94 (Table 2). The standard quercetin has an Rf value of 0.45 . The chromatogram and the densitogram (Figs. 3 and 4) of the extract illustrate that the sample possesses the compound quercetin and other flavonoids with higher concentration. The HPTLC chromatogram was examined under daylight, UV $254 \mathrm{~nm}$, and UV $366 \mathrm{~nm}$.

\section{Terpenoids}

HPTLC slides developed at UV $254 \mathrm{~nm}$ and UV $366 \mathrm{~nm}$ in the Figs. (5 and 6) showed that four different terpenoid compounds were found to be present in the ethanolic extract of OBT, with the Rf values of $0.04,0.36$, 0.49 , and 1.06. Lupeol was used as a standard with the Rf value 1.08. Apart from the Rf values, the peak areas were compared. The peak areas in the Table 3 are as follows: 15289.6, 23745, 18329, 15224, 19486, $44392,17441,15841.6$, and 60872.4 , and this showed that flavonoids other than lupeol were also present with very higher concentration.

\section{DPPH scavenging assay}

The antioxidant activity of OBT was evaluated using an alcoholic solution of the stable free radical DPPH. The free radical scavenging activity of the extract was found to be dose-dependent, and the results were compared with positive control ascorbic acid. The percentage of DPPH scavenging capacity of the extract indicated the sensitivity of the assay toward water-soluble antioxidants. The $\mathrm{IC}_{50}$ value of OBT and ascorbic acid for DPPH scavenging activity was found as 372.22 and $80.78 \mu \mathrm{g} / \mathrm{ml}$, respectively (Fig. 7).

\section{Superoxide scavenging activity}

Ethanolic extract of OBT displayed a dose-dependent effect in scavenging superoxide radicals, and the results were compared with

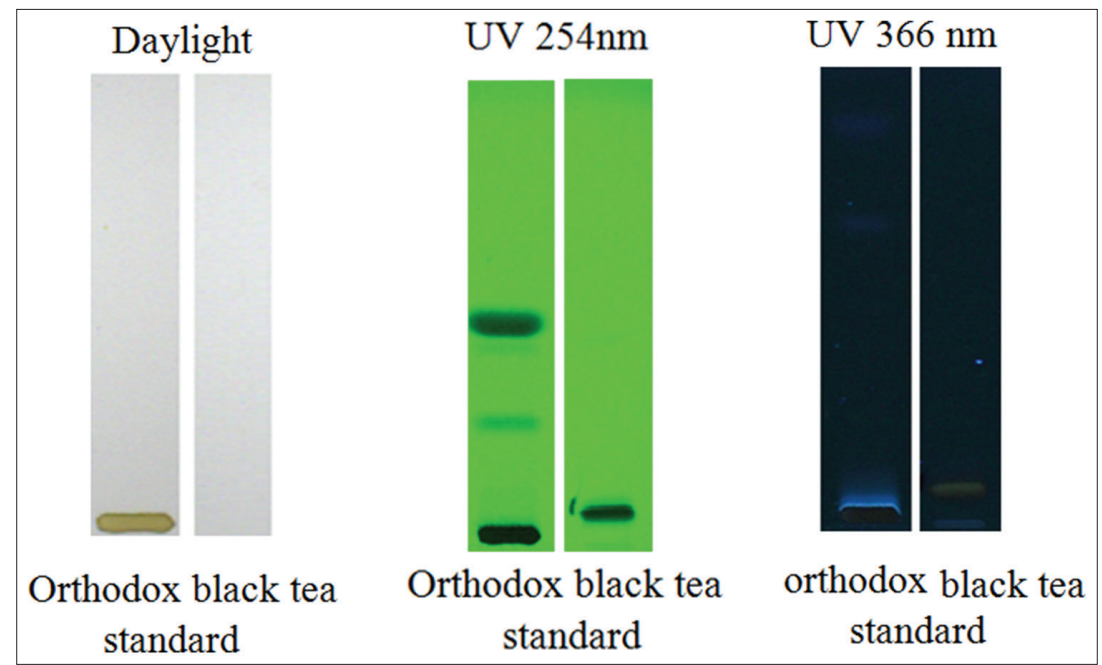

Fig. 1: Chromatograms of extract in high-performance thin-layer chromatography for alkaloid analysis: Under daylight, UV 254 nm, and UV $366 \mathrm{~nm}$ 
known antioxidant quercetin. The $\mathrm{IC}_{50}$ value for superoxide scavenging activity for OBT was found as $311.93 \mu \mathrm{g} / \mathrm{ml}$ (Fig. 8). At $500 \mu \mathrm{g} / \mathrm{ml}$, the percentage of inhibition was found as $74.15 \%$.

\section{NO radical scavenging activity}

The OBT showed a dose-dependent inhibition of NO with an $\mathrm{IC}_{50}$ of $52.0 \mu \mathrm{g} / \mathrm{ml}$ (Fig. 9). Quercetin was used as a reference compound and $362.17 \mu \mathrm{g} / \mathrm{ml}$ quercetin was needed for $50 \%$ inhibition. At $500 \mu \mathrm{g} / \mathrm{ml}$, the percentage of inhibition was found as $65.42 \%$ for the extract.

Table 3: Peak table with Rf values, height, and area of terpenoids and unknown compounds

\begin{tabular}{llllll}
\hline Track & Peak & Rf value & Height & Area & $\begin{array}{l}\text { Assigned } \\
\text { substance }\end{array}$ \\
\hline Standard & 1 & 1.08 & 6.6 & 3368 & Lupeol \\
Sample & 1 & 0.02 & 468.5 & 7434.5 & Unknown* \\
Sample & 2 & 0.04 & 421.7 & 15289.6 & Terpenoid 1 \\
Sample & 3 & 0.16 & 376.6 & 23745.5 & Unknown* \\
Sample & 4 & 0.24 & 375.0 & 18329.0 & Unknown* \\
Sample & 5 & 0.30 & 365.3 & 15224.0 & Unknown* \\
Sample & 6 & 0.36 & 616.5 & 19486.0 & Terpenoid 2 \\
Sample & 7 & 0.49 & 200.6 & 44392.6 & Terpenoid 3 \\
Sample & 8 & 0.62 & 201.4 & 17441.2 & Unknown* \\
Sample & 9 & 0.76 & 225.6 & 15841.6 & Unknown* \\
Sample & 10 & 1.06 & 98.8 & 60872.4 & Terpenoid 4 \\
\hline
\end{tabular}

Rf: Retention factor
The hydroxyl radical scavenging activity of the extract correlated well with increasing concentration. The effect was compared with the standard antioxidant $\alpha$-tocopherol and the $\mathrm{IC}_{50}$ values of the extract and $\alpha$-tocopherol were 342.14 and $236.41 \mu \mathrm{g} / \mathrm{ml}$, respectively (Fig. 10). However, as anticipated, the activity of $\alpha$-tocopherol was relatively more pronounced than the extract.

\section{Reducing power}

The effect of OBT on reducing power was studied according to the reaction of $\mathrm{Fe}^{3+}$ to $\mathrm{Fe}^{2+}$. The results were compared with the reference compound ascorbic acid (Fig. 11). The $\mathrm{IC}_{50}$ values of the extract and ascorbic acid were 178.54 and $120.38 \mu \mathrm{g} / \mathrm{ml}$, respectively.

\section{DISCUSSION}

The components of tea possess various bioactive principles which act as antioxidants antimutagenic and anticarcinogenic agents, and hence, it has magnetized the interest of people due to its enormous health benefits. These bioactive principles protect us from various environmental factors which cause diseases [17]. Those diseases become a serious public health issues. A huge amount of synthetic drugs exist in the market against various diseases and involve in adverse drug effect. An alternate is the consumption of natural compounds elucidated from plants and food supplements (functional foods). Such natural compounds have isolated and determined for its therapeutic property [18].

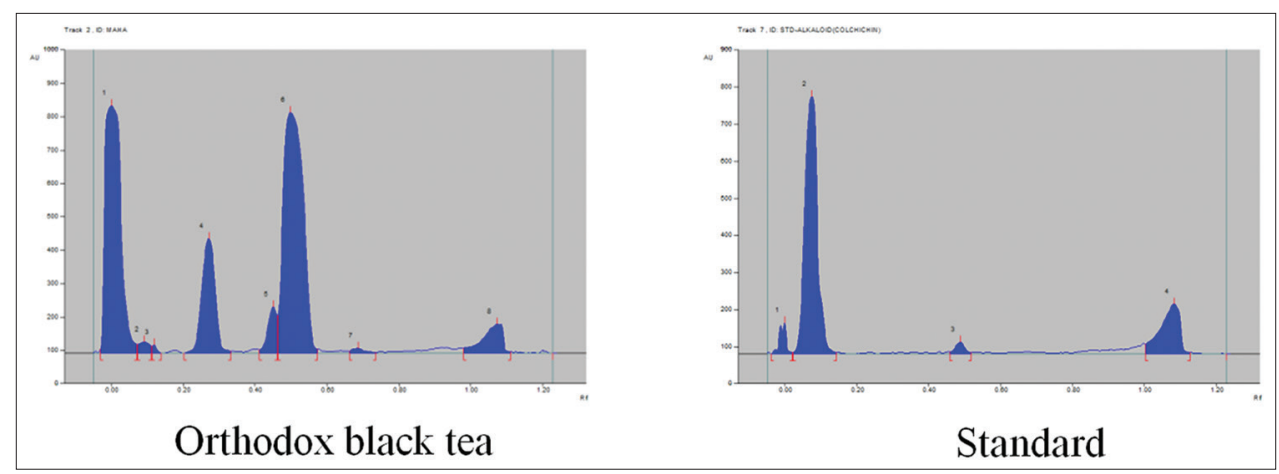

Fig. 2: High-performance thin-layer chromatography densitogram of alkaloids in standard colchicine and orthodox black tea

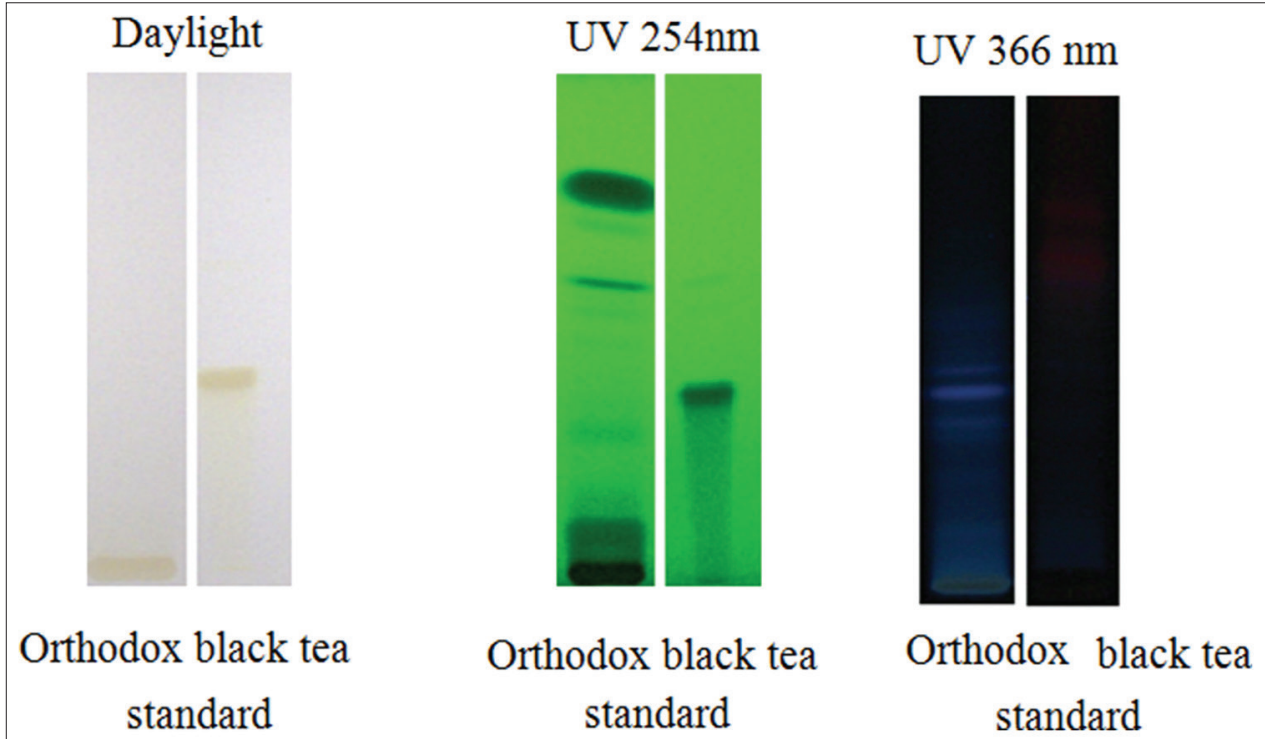

Fig. 3: Chromatograms of extract in high-performance thin-layer chromatography for flavonoid analysis: Under daylight, UV $254 \mathrm{~nm}$, and UV $366 \mathrm{~nm}$ 


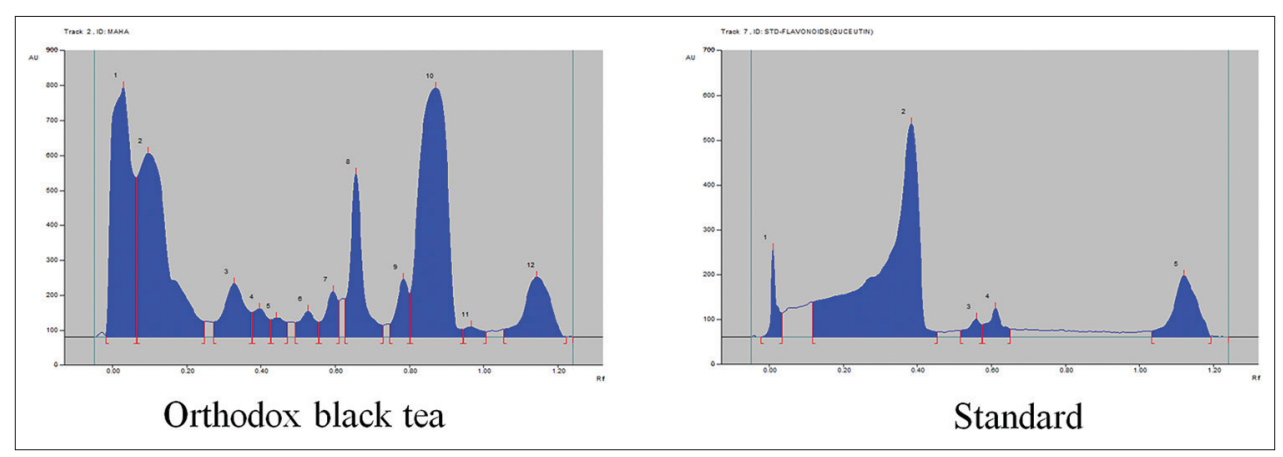

Fig. 4: High-performance thin-layer chromatography densitogram of flavonoids in standard quercetin and orthodox black tea

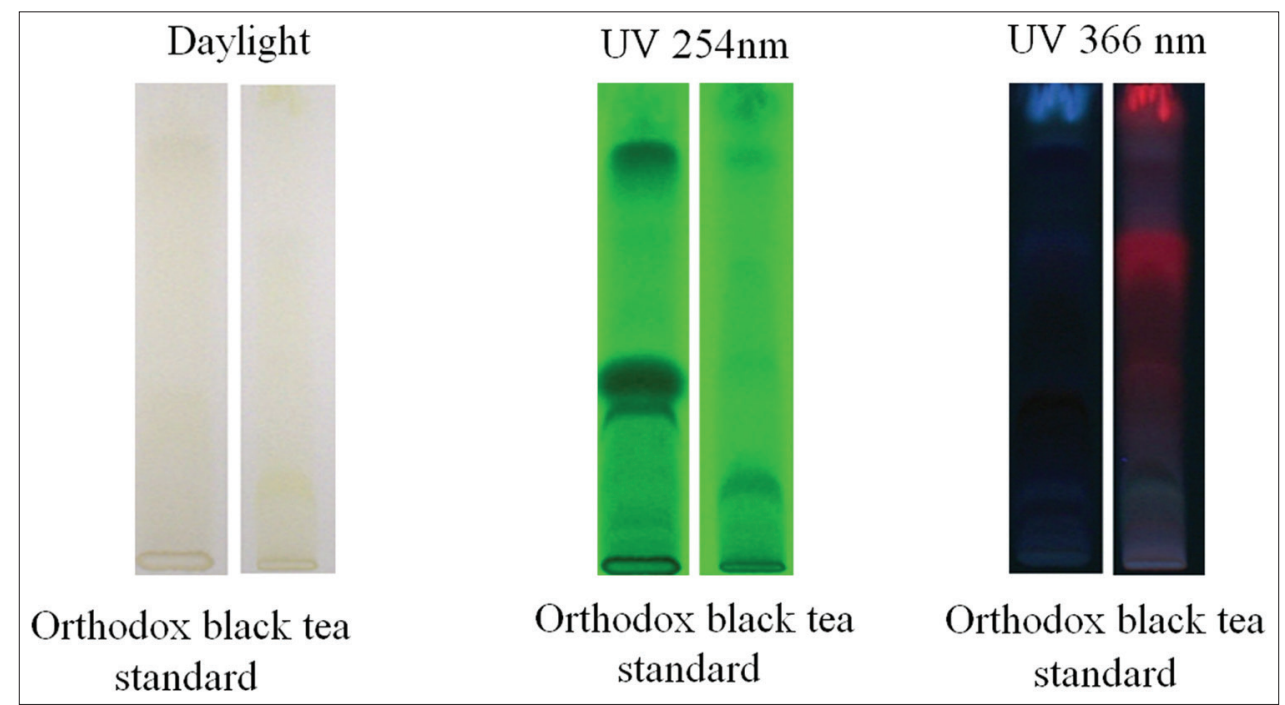

Fig. 5: Chromatograms of extract in high-performance thin-layer chromatography for terpenoids analysis: Under daylight, UV $254 \mathrm{~nm}$, and UV $366 \mathrm{~nm}$

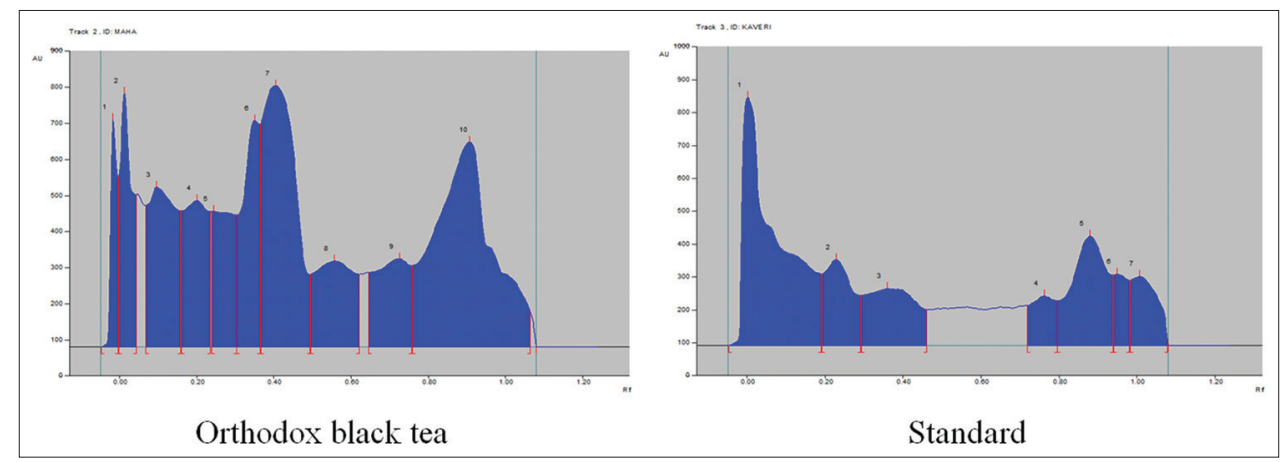

Fig. 6: High-performance thin-layer chromatography densitogram of terpenoids in standard lupeol and orthodox black tea

Various parts of the plant were used traditionally for the treatment of several diseases. The development in the technology increased theinterest among the researchers to know the active principles (phytochemicals) present in the medicinal plants. The present investigation revealed the antioxidant property of an unexplored variety of tea using in vitro assessment [19]. The total phenolic and flavonoid content was carried out in the OBT and compared with the standard antioxidants. This present study revealed the antioxidant property of the extract.

The DPPH radical scavenging activity of OBT clearly showed that it possesses the property in a dose-dependent fashion with ascorbic acid as standard. It is illustrious that phenolic compounds are potential antioxidants, and hence, there should be a close connection between the content of phenolic compounds and its antioxidant activity [20].
Huge biological damage was caused by the major active oxygen species, hydroxyl radical. Free radicals initiate the polymerization reaction and other oxidizing reaction. The free radical scavengers in the plant extract inhibit the oxidation process initiated by radicals [21]. Free radical was found to be removed by the addition of OBT, which was compared against the standard $\alpha$-tocopherol. Harmful reactive oxygen species were formed from superoxide radical such as hydrogen peroxide and hydroxyl radical. These radicals, in turn, damage the biomolecules which lead to dreadful diseases. The OBT had greater superoxide radical scavenging activity. The substance which involved in scavenging the radical might be the polyphenolic compounds present in the extract [22]. These antioxidants contribute significantly toward the biological activities such as hypoglycemic, antidiabetic, antimicrobial, 


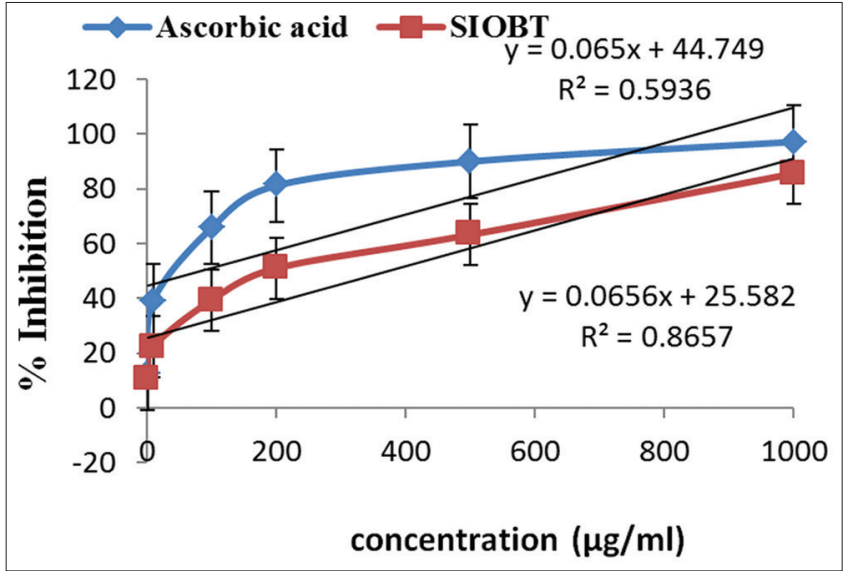

Fig. 7: 2,2-diphenyl-1-picrylhydrazyl radical scavenging activity of orthodox black tea

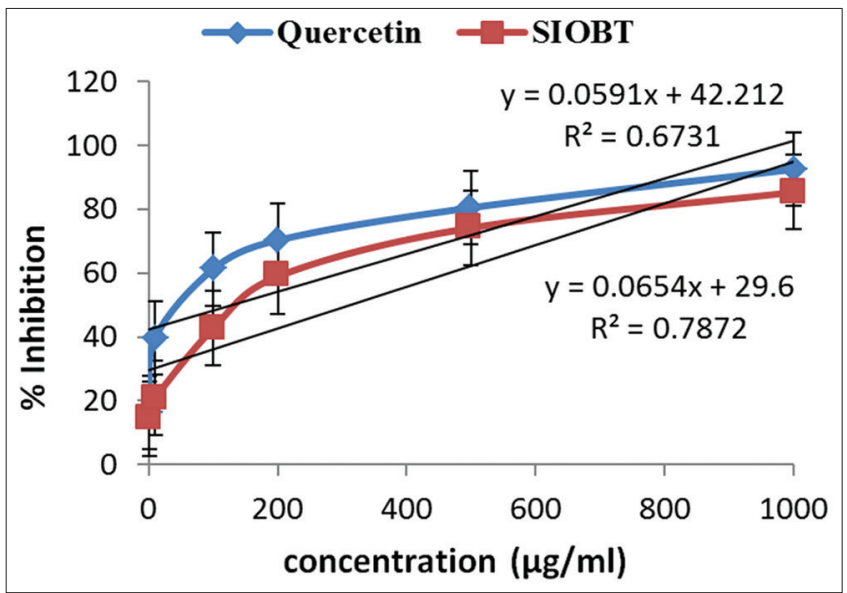

Fig. 8: Superoxide radical scavenging activity of orthodox black tea

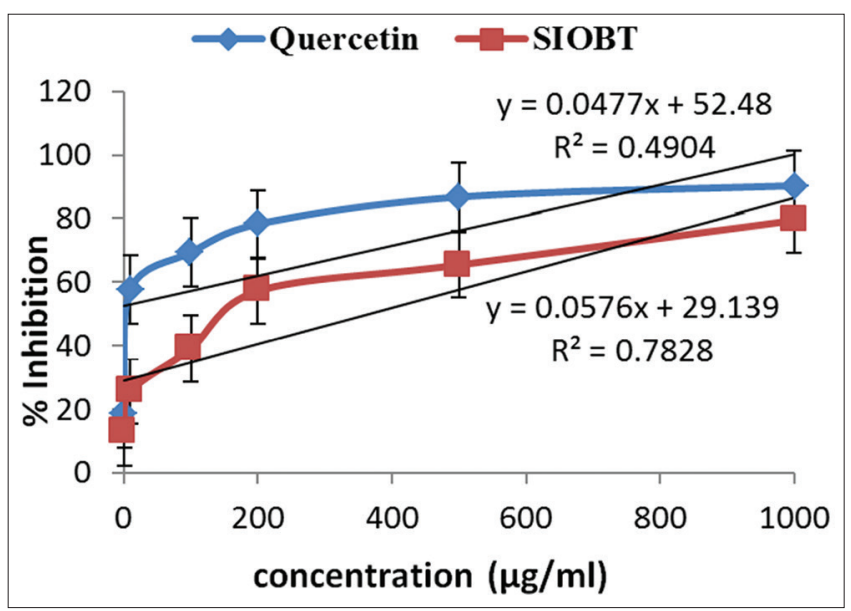

Fig. 9: Nitric oxide radical scavenging activity of orthodox black tea Hydroxyl radical scavenging activity

antioxidant, anti-inflammatory, anticarcinogenic, antimalarial, and anti-leprosy activities [23].

Mammalian cells involve in the regulation of enormous physiological process which ends up with the production of NO radical; furthermore, the amount of NO radical increases even during ailments. Thus, the production of radicals can be prevented with the aid of free radical

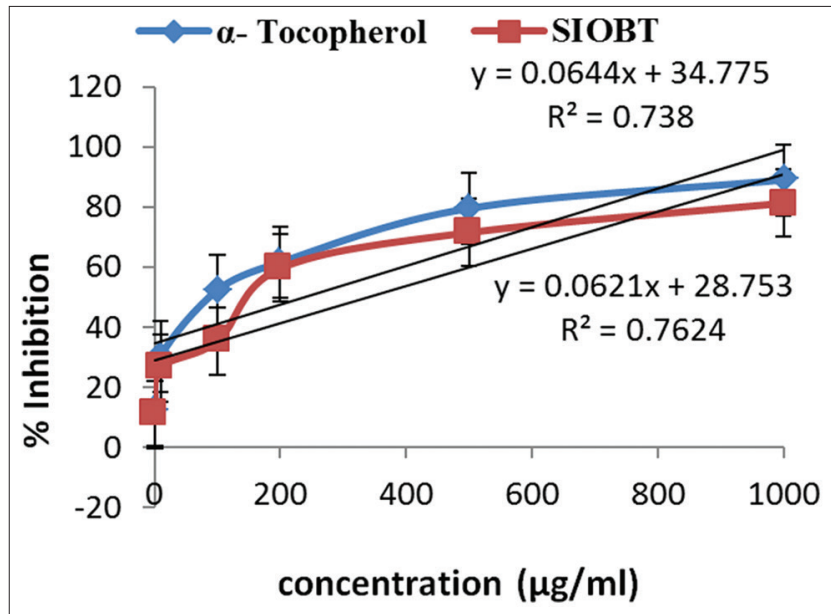

Fig. 10: Hydroxy radical scavenging activity of orthodox black tea

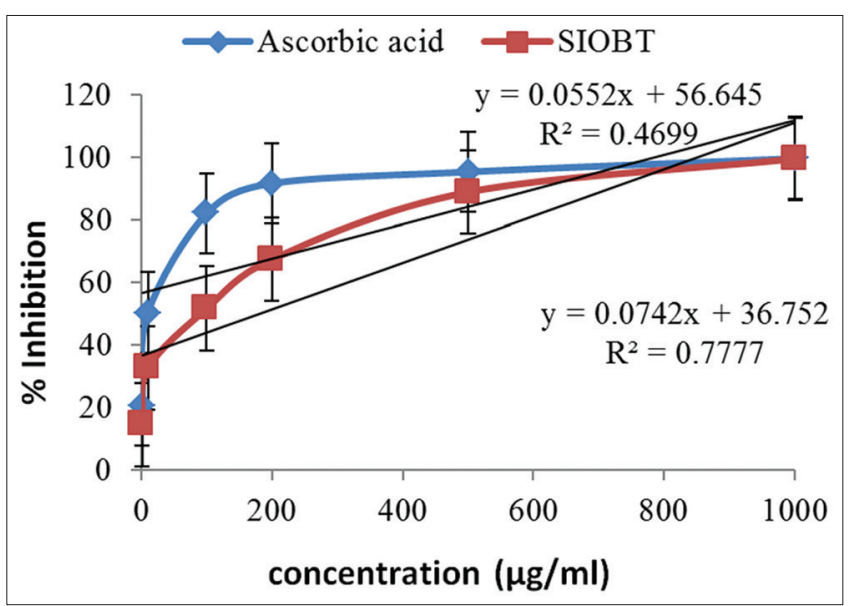

Fig. 11: Reducing power activity of orthodox black tea

scavengers [24]. In the present study, we deducted the NO scavenging activity of OBT and also compared with standard quercetin. The compound with the characteristics of reducing the radical is the good sign of antioxidants. The reductors lend electron to the radicals and thereby cease the radical chain reaction forming stable compounds. The study revealed that the extract possesses similar reducing power compared with ascorbic acid as standard [25].

\section{CONCLUSION}

The existence of the phytochemical constituents was identified using HPTLC analysis in ethanolic extract of OBT. The presence of alkaloids, flavonoids, and terpenoids was identified for its presence with the peaks and the retardation factor (Rf value) obtained for the extract and compared with the peaks obtained for the standard. The HPTLC analysis of the OBT suggested the presence of potential therapeutic substances in preventing and curing the disease.

\section{AUTHOR'S CONTRIBUTION}

This work was done by the authors named in this article and all liabilities pertaining to claims relating to the content of this article will be borne by the authors. R. Mahalakshmi carried out the experiments and had written the manuscript. Dr. A. Nishadh helped in all the laboratory work. Dr. K. Kalaivani designed the work, proofread, and validated the manuscript.

\section{CONFLICTS OF INTEREST}

The authors declare no conflicts of interest of this study. 


\section{REFERENCES}

1. Sharma RK, Bhagwan D. Charak Samhita. $4^{\text {th }}$ ed., Vol. 2. Varanasi: Chowkhamba Sanskrit Series; 1996. p. 17-101.

2. Jigisha A, Bhagwati U, Pramod R, Nishant R. Biochemical characterization and pharmacognostic evaluation of purified catechins in green tea (Camellia sinensis) cultivars of India. 3 Biotech 2015;5:285-94.

3. Kumar RS, Muraleedharan NN, Murugesan S, Kottur G, Anand M, Nishadh A. Biochemical quality characteristics of CTC black teas of south India and their relation to organoleptic evaluation. Food Chem 2011;129:117-24.

4. Shaikh NI, Sumaya F, Amit S. Effect of consecutive steeping on antioxidant potential of green, oolong and black tea. Int J Food Sci Tech 2018;53:182-7.

5. Basu MA, Bera B, Rajan A. Tea statistics: Global scenario. Int J Tea Sci 2010;8:121-4.

6. Asha D, Lizzy M, Rishad KS. Evaluation of HPTLC fingerprints of flavonoids and antioxidant activity of selected medicinal plants of Lamiaceae family. Int J Pharmacog Phytochem Res 2015;7:240-5.

7. Budryn G, Nebesny E, Rachwal-Rosiak D, Oracz J. Fatty acids, essential amino acids, and chlorogenic acids profiles, in vitro protein digestibility and antioxidant activity of food products containing green coffee extract. Int Food Res J 2013;20:2133-44.

8. Blois MS. Antioxidant determinations by the use of a stable free radical. Nature 1958;181:1199-200.

9. Halliwell B, Gutteridge J. Formation of a thiobarbituric-acid-reactive substance from deoxyribose in the presence of iron salts: The role of superoxide and hydroxyl radicals. FEBS Lett 1981;128:347-52.

10. Jayaprakasha GK, Jaganmohan RL, Sakariah KK. Antioxidant activities of flavidin in different in vitro model systems. Bioorg Med Chem 2004;12:5141-46.

11. Sanchez-Moreno C. Methods used to evaluate the free radical scavenging activity in foods and biological systems. Food Sci Technol Int 2002;8:121-37.

12. Green LC, Wagner DA, Glogowski J, Skipper PL, Wishnok JS, Tannenbaum SR. Analysis of nitrate, nitrite, and $\left({ }^{15} \mathrm{~N}\right)$ nitrate in biological fluids. Anal Biochem 1982;126:131-8.

13. Yildirim A, Mavi A, Kara AA. Determination of antioxidant and antimicrobial activities of Rumex crispus L. extracts. J Agric Food
Chem 2001;49:4083-9.

14. Manju S, Chandran RP, Shaji PK, Nair GA. In vitro free radical scavenging potential of Acorus calamus L. rhizome from Kuttanad Wetlands Kerala, India. Int J Pharm Pharm Sci 2013;5:376-80.

15. Chacko SM, Thambi PT, Kuttan R, Nishigaki I. Beneficial effects of green tea: A literature review. Chin Med 2010;5:1-9.

16. Yildirim A, Mavi A, Oktay M, Kara AA, Algur OF, Bilaloglu V. Comparison of antioxidant and antimicrobial activities of tilia (Tilia arentea Desf. Ex. D.C.) sage (Salvia triloba L.) and black tea (Camellia sinensis L.) extracts. J Agr Food Chem 2000;48:5030-4.

17. Camargo LE, Pedroso LS, Vendrame SC, Mainardes RM, Khalil NM. Antioxidant and antifungal activities of Camellia sinensis (L.) Kuntze leaves obtained by different forms of production. Braz Biol 2016;76:428-34

18. Li P, Huo L, Su H, Lu R, Deng C, Liu L, et al. Free radicalscavenging capacity, antioxidant activity and phenolic content of Pouzolzia zeylanica. J Serb Chem Soc 2011;76:709-17.

19. Nagarajan A, Sellamuthu M. Antioxidant and free radical scavenging potential of different solvent extracts of Indigofera tinctoria L. leaves. Int J Pharm Pharmacol Sci 2013;5:142-7.

20. Usha V, Suriyavathana M. Free radical scavenging activity of ethanolic extract of Desmodium gangeticum. J Acute Med 2012;2:36-42.

21. Vadivukkarasi S, Pavithra K. Evaluation of free radical scavenging activity of various leaf extracts from Kedrostis foetidissima (Jacq.) Cogn. Biochem Anal Biochem 2014;3:1-7.

22. Demiray S, Pintado ME, Castro PML. Evaluation of phenolic profiles and antioxidant activities of Turkish medicinal plants: Tilia argentea, Crataegi folium leaves and Polygonum bistorta roots. World Acad Sci Eng Technol 2009;54:312-7.

23. Nishadh A. Evaluation of enzymic and non-enzymic antioxidant levels in Vernonia cinerea extracts. Asian J Pharm Clin Res 2018; 11 (7): 167-70.

24. Sreedevi P, Vijayalakshmi K. Determination of antioxidant capacity and gallic acid content in ethanolic extract of Punica granatum L. leaf. Asian J Pharm Clin Res 2018;11:319-23

25. Gurupriya S, Cathrine L, Pratheema P. HPTLC method for the determination of lupeol from Andrographis echioides leaves. Int $\mathrm{J}$ Pharm Pharm Sci 2018;10:102-7. 